\title{
Estimation of Stem Cell Content in Infranatant Fraction of Lipoaspirate
}

\author{
ASSEM H. KAMEL, M.D.*; MOHAMED MAKBOUL, M.D.*; AHMED M. TOHAMY, M.D.*; \\ FATMA YASSIN, M.D.** and EHAB RAGAB, M.D.* \\ The Department of Plastic \& Reconstructive Surgery* and Histology**, Faculty of Medicine, Assiut University
}

\begin{abstract}
Background: Stem cells are considered a powerful tool in regenerative medicine nowadays, adipose tissue is rich source of ADSCs and as product of liposuction the lipoaspirate is used to isolate ADSCs from it.

Purpose: Evaluation of stem cell content, density, immunephenotyping and electron microscopic structure in the infranatant fraction of liposuction aspirate and compare the results with that obtained from fat fraction of lipoapirate using traditional method.

Methods: This study was conducted on twenty-five patients from which 100 specimens was isolated those patients were attending the Outpatient Clinic of Plastic Surgery Department at Assiut University Hospital seeking body contouring between April, 2015 and September, 2016. In this study we evaluated the stem cell content in liposuction aspirate Infranatant fluid and fat from two different sites (abdomen and thigh).

Results: Comparing between the range and mean of the number of viable ADSC isolated from infranatant of lipoaspirate with that isolated from fat fraction using collagenase a high statistical significance, the mean $11.47 / \mathrm{ml}$ while from fat fraction using collagenase was $133.08 / \mathrm{ml}$. with a significant statistical difference with a $p$-value of 0.000 (values are per $1 \mathrm{ml}$ and multiplied by $10^{4}$ ). Regarding the comparison of the means of the two harvesting sites (thigh and abdomen) by both methods we found that ADSCs was higher in the abdomen than those from the thigh but however the results were statistically insignificant with a $p$-value $>0.05$.

Conclusions: Infranatat fluid of lipoaspirate is not a waste product and shouldn't be discarded, it is a rich source of ADSCs, Time factor using infranatant fluid for stem cells is much less than that of fat using digestive enzymes and more economic.
\end{abstract}

Key Words: Stem cell - ADSC - Regenerative medicine.

\section{INTRODUCTION}

Most tissues in the body have their own stem cells, which have the ability to produce mature cells of that specific tissue. Their job is to replenish cells of that tissue when old cells die. Muscles, skin, nerves, and the liver are examples of tissues and organs where stem cells can be found [1].

The original, pioneering work on the isolation of adipose-derived stem cells (ASCs) from liposuction waste typically involves 8-10 hours of continuous intense effort, making it a laborintensive endeavor and increasing the risk of culture contaminations due to excessive handling $[2,3]$.

To make stem cell therapy more established standard treatment, a larger number of upcoming clinical study is necessary. Further research about determining the fate of transplanted cells and numbering of cells required for definitive clinical effects should be followed. The adverse effects of cell transplantation, possibility of tumor growth and long-term results of these cells should also be validated. Good manufacturing practice (GMP) facilities are mandatory for safe collection, testing and cryopreservation of customer's cells thus we need an easy reproductive method of isolation to make further studies easier and more applicable [4].

The aim of our study was to estimate the amount of Adipose derived stem cell content in the infranatant fluid fraction of lipoaspirate from two different sites (abdomen and thigh) and compare it with that obtained from fat fraction with traditional methods using digestive enzymes.

\section{MATERIAL AND METHODS}

This study was conducted on lipoaspirate; from patients asking for body contouring by liposuction. A hundred specimens from the infranatant fluid fraction of the lipoaspirate and another hundred specimen obtained from the fat fraction (Fig. 1). 


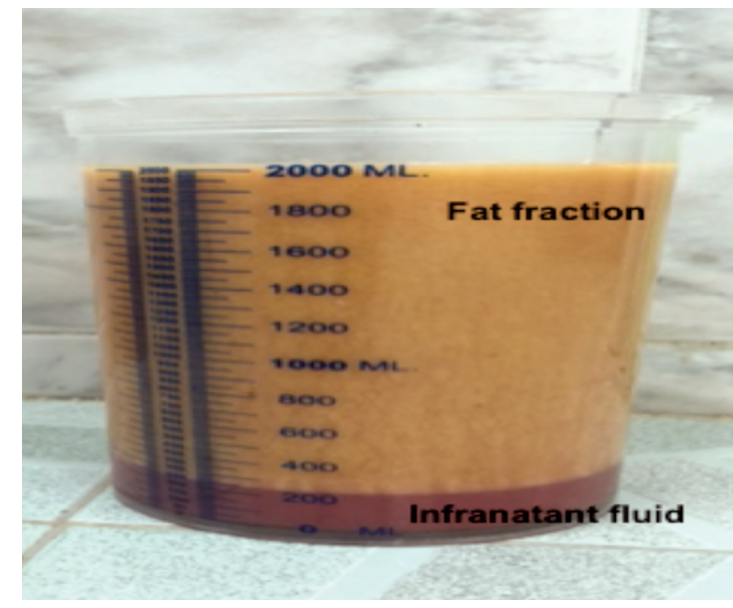

Fig. (1): Lipoaspirate separated into the four layers upper oily, fatty layer, infranatant fluid and the lowermost bloody layer fractions.

In the sites to be treated with liposuction, we infiltrated normal wetting solution (Epinephrine $1 \mathrm{mg}$ for each $500 \mathrm{ml}$ of lactated ringer's solution).

Aspiration begins 20 minutes after infiltration in all cases. We used the traditional liposuction we used 5.0 Mercedes cannula in obtaining the specimens and a suction device (Nouvag Swiss made) the power of suction 0.9 bar and the device flow rate was $(60 \mathrm{~L} / \mathrm{min}$.) and this was used in harvesting. All specimens lipoaspirate was collected in sterile jars.

Specimens from the fat fraction in which collagenase enzyme was used. Specimens were washed with equal volume of phosphate buffer solution (PBS) 3-4 times until clear.

We allowed enzymatic digestion of fat by adding collagenase enzyme solution in equal amount of fat that needs to be digested.

Then the mixture was placed in a shaking water bath at 37 degrees for 1 hour. Collagenase effect was neutralized by adding fetal bovine serum $10 \%$ (FBS).

Then we put the specimen in $50 \mathrm{ml}$ conical tubes. The tubes were placed in Centrifugation machine at $1,000 \mathrm{xg}$ for $10 \mathrm{~min}$ to separate the oil and remaining fat lobules from the stromal vascular fraction (SVF).

While specimens from the infranatant fluid fraction were centrifuged at $400 \mathrm{xg}$ for $10 \mathrm{~min}$, then Red Blood Cell lyses with $160 \mathrm{mM} \mathrm{NH} 4 \mathrm{Cl}$ for $5 \mathrm{~min}$. And final centrifugation for $10 \mathrm{~min}$ at $400 \mathrm{xg}$ was done to obtain the final pellet of stem cells (Fig. 2).

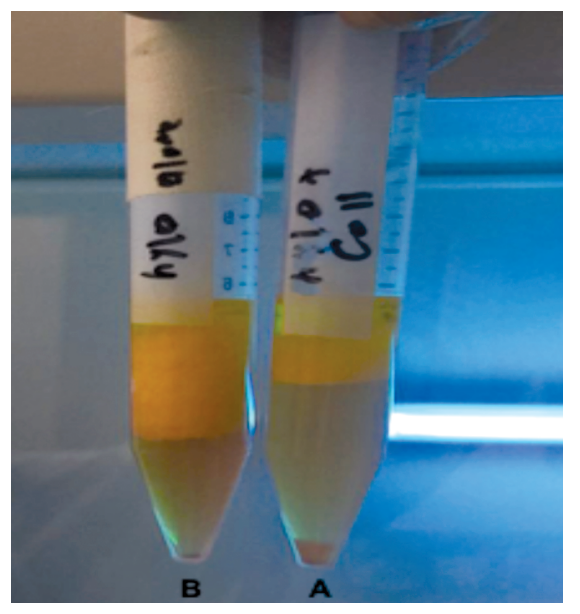

Fig. (2): Conical tubes after centrifugation showing cell pellets in SVF (Tube A showing pellets using collagenase, Tube B showing pellets using hyaluronidase alone).

\section{Identification by immunophenotyping using flowcytometry:}

The isolated ASCs from both fractions of lipoaspirate were characterized for the expression of the markers CD90 and CD45 by taking cells from the pellet for each method of isolation.

\section{Counting of (ADSC) using trypan blue stain:}

Before the cells have a chance to settle, we took out $0.5 \mathrm{~mL}$ of cell suspension using a $5 \mathrm{~mL}$ sterile pipette and placed in an Eppendorf tube and then we added $0.5 \mathrm{ml}$ of trypan blue stain and mixed them together in this Eppendorf tube.

Using a microscope, we focused on the grid lines of the hemocytometer with a 10X objective. We counted the viable unstained cells (live cells do not take up trypan Blue) in the 4 corners of the hemocytometer.

Ultrastructural analysis using transmission electron microscopy (TEM):

The cell pellet of (ADSCs) from each method of isolation was taken and fixed with $2.5 \%$ glutaraldehyde in phosphate buffer $0.1 \mathrm{M}, \mathrm{pH} 7.4$, for 24 hours at $4 \mathrm{C}$ and then post fixed with $1 \% \mathrm{OsO} 4$ in the same buffer for 1 hour at room temperature. Samples were dehydrated in ascending grades of alcohol and embedded in epoxy resin. Ultra-thin sections will be counterstained with lead citrate and uranyl acetate and examined using under TEM (JEM) - (1200EX) (JEOL Ltd., USA).

\section{Statistical analysis:}

The data were collected and inserted in $\mathrm{Mi}-$ crosoft Excel to be analyzed using the Statistical Package for Social Science (SPSS Inc., Chicago, 
Version 24). Data were statistically described in mean \pm SD and range. Mann-Whitney Test was used to analyze data. The difference was considered significant when $p$-value is $<0.05$.

\section{RESULTS}

Regarding the comparison of the mean and range of the number of viable ADSC isolated from fat fraction in $1 \mathrm{ml}$, mean of $133.08 / \mathrm{ml}$, with that from infranatant fluid fraction which was $11.47 / \mathrm{ml}$ the comparison was of high statistical significance with a $p$-value $<0.05$ (Table 1 ). All the numbers are multiplied by $104 / \mathrm{ml}$ of pellet, the specimens for both groups were $50 \mathrm{cc}$ and gave $2 \mathrm{ml}$ pellet.

Table (1): Comparison between then number of viable ADSCs by different methods.

\begin{tabular}{lccc}
\hline & Infranatant fluid & Fat fraction & $p$-value \\
\hline Mean \pm SD & $11.47 \pm 3.00$ & $133.08 \pm 16.41$ & \\
Range & $6.0-19.0$ & $102.0-161.0$ & $0.000^{*}$ \\
\hline
\end{tabular}

* Statistical significant difference $(p<0.05)$.

Regarding the comparison of the means of the two harvesting sites by both methods ADSCs was higher in the abdomen than those from the thigh but however the results were statistically insignificant with a $p$-value $>0.05$ (Table 2).

Table (2): Comparison between then number of viable ADSCs by different methods as regarding site.

\begin{tabular}{llll}
\hline & \multicolumn{3}{c}{ Site } \\
\cline { 2 - 4 } & Abdomen & \multicolumn{1}{c}{ Thigh } & $p$-value \\
\hline $\begin{array}{l}\text { Isolation by } \\
\text { collagenase: } \\
\quad \text { Mean } \pm \text { SDA }\end{array}$ & $138.71 \pm 19.53$ & $125.20 \pm 5.97$ & 0.088 \\
$\quad$ Range & $102-161$ & $119-133$ & \\
Infranatant fluid: & & & \\
$\quad$ Mean \pm SD & $12.20 \pm 3.39$ & $10.43 \pm 2.15$ & 0.401 \\
$\quad$ Range & $8-19$ & $6-12$ & \\
\hline
\end{tabular}

Flow cytometric expression of ADSCs, analysis of isolated stem cells demonstrated that isolated populations of ADSCs were positive from fat using Collagenase enzyme ( $72 \%$ and $72 \%$ ), while it showed 15\% (Fig. 3).

Transmission electron microscopic (TEM) evaluation of quality of enzyme dissociation:

Under TEM, the cytoplasm of the isolated ASCs was moderately electron-dense. It contained numerous mitochondria and rough endoplasmic reticulum and electron-dense material.

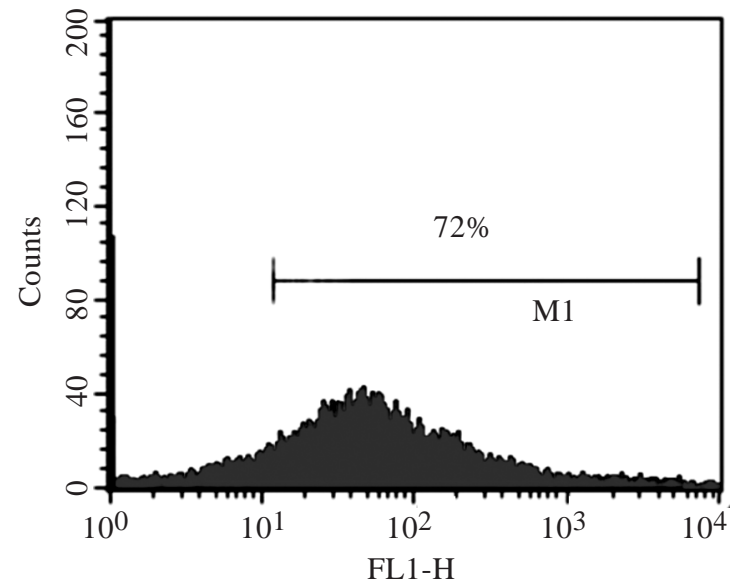

Fat using collagenase

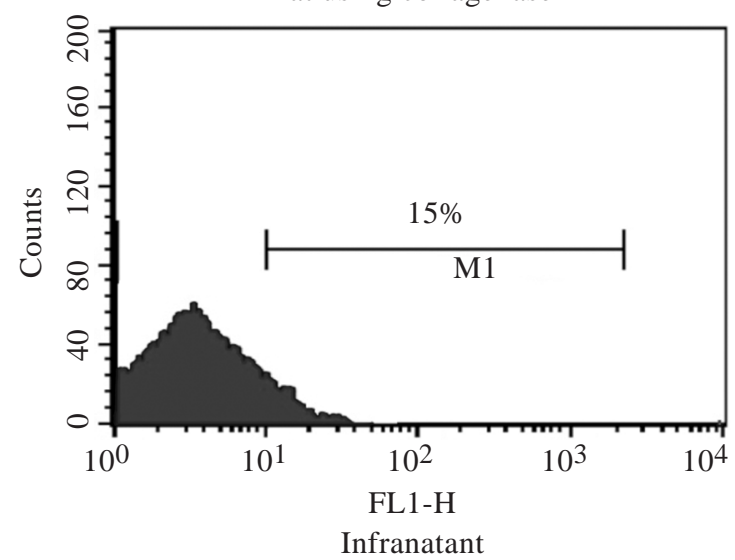

Fig. (3): Histograms showing flow cytometric expression of the ADSC marker CD90.

ASCs isolated from the lipoaspirate from both fractions revealed large nuclei $(\mathrm{N})$, located at one side of the cell and intact cellular membrane (Fig. $4)$.

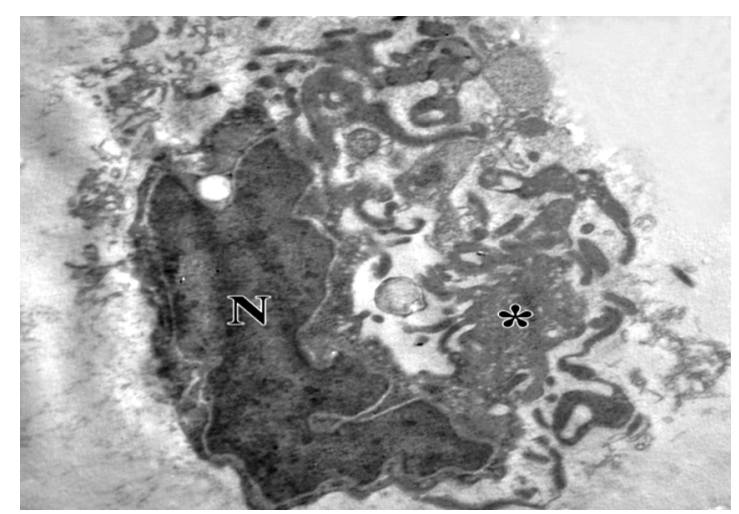

Fig. (4): Electron microscopic image of stem cell isolated.

\section{DISCUSSION}

Liposuction is a frequently performed cosmetic surgical procedure and the aspirated adipose tissue is usually discarded. However, this tissue is a rich source of ASC and so can be used without culturing in treatments requiring ASC. Nevertheless, they 
still need to be enzymatically digested and centrifuged before transplantation to be more concentrated if more ASC are needed [5].

Comparing thigh and abdominal regions as donor sites, we found that isolated populations of ADSCs were statistically insignificant although higher in the abdomen from that of the thigh in both groups. These findings coincided with results reported that harvests from the abdomen, flank and thigh, all produced a statistically equivalent number of viable cells and also coincides with Faustini et al., [6,7], whose work showed that ADSCs yield taken from the different sites did not influence the yield of ADSCs isolated from lipoaspirate.

From the infranatat fluid of the lipoaspirate we isolated ADSCs and had a mean which is in accordance with the work of Francis et al., 2010 and Bowen, $[\mathbf{8 , 9}$ ] who also isolated ADSCs from the infranatant fluid of lipoaspirate and the yield of our work and theirs ranges is $(9-11 \times 104 / \mathrm{ml})$.

In our study we used collagenase for enzymatic digestion of fat in group A. The mean of the cell count after isolation using collagenase alone was in accordance with those studies published by $\mathrm{Yu}$ and his colleagues [10], and Buschmann with his colleagues [11] the range of means in all these studies is $(96 \times 138 \times 104 / \mathrm{ml})$.

Comparing the yield of ADSCs from both fractions of lipoaspirate. We obtained more cells from fat than that from the infranatat fluid it was about the mean from fat was about 10 folds the mean of ADSCs from infranatant fluid and that was of statistical significance.

Flowcytometry has also been used in our study to analyze the expressions of cell-surface markers which is a general strategy for identifying ADSCs. CD44, CD90 were used and there was positive expression from both methods.

Transmission electron microscopic examination of ADSCs allowed evaluation of the ultra-structural details of ADSCs. The results in our study with showed that there was no alteration in the ultrastructure of ADSCs isolated by different methods and coincides with the electron microscopic structure described by Yang and his colleagues [12].

The time needed to obtain ADSCs from the infranatant fluid is much less than that using digestive enzymes in fat which takes about 8 hours while from the infranatat fluid it takes around 1 hour to obtain the pellets, this method has also the advantage of needing less equipment and doesn't require specialized personnel and it has lower cost, Although the yield is much lower than that from fat using collagenase, however in large amounts of infranatant fluid this method can yield millions of ADSCs considering its easier technique.

\section{Conclusion:}

Infranatat fluid of lipoaspirate is not a waste product and shouldn't be discarded, it is a rich source of ADSCs.

Although the cell content obtained from the infranatant fluid is much less than that obtained from the fat, in large amounts of infranatant fluid it can yield much more cells compared to fat when taking its easy applicability in mind.

Time factor using infranatant fluid for stem cells is much less than the time needed to obtain ADSCs using digestive enzymes from fat and also more economic.

\section{REFERENCES}

1- Murry C.E., Soonpaa M.H., Reinecke H., Nakajima H., Nakajima H.O., Rubart M., Pasumarthi K.B., Virag J.I., Bartelmez S.H., Poppa V. and Bradford G.: Haematopoietic stem cells do not transdifferentiate into cardiac myocytes in myocardial infarcts. Nature. Apr., 8; 428 (6983): 6648, 2004.

2- Gimble J.M. and Guilak F.: Adipose-derived adult stem cells: Isolation, characterization, and differentiation potential. Cytotherapy. Jan., 1; 5 (5): 362-9, 2003.

3- Huang J.I., Zuk P.A., Jones N.F., Zhu M., Lorenz H.P., Hedrick M.H. and Benhaim P.: Chondrogenic potential of multipotential cells from human adipose tissue. Plastic and Reconstructive Surgery. Feb., 1; 113 (2): 585-94, 2004

4- West C.C., Murray I.R., González Z.N., Hindle P., Hay D.C., Stewart K.J. and Péault B.: Ethical, legal and practical issues of establishing an adipose stem cell bank for research. Journal of Plastic, Reconstructive \& Aesthetic Surgery. Jun., 30; 67 (6): 745-51, 2014.

5- Kishi K., Imanishi N., Ohara H., Ninomiya R., Okabe K., Hattori N., Kubota Y., Nakajima H. and Nakajima T.: Distribution of adipose-derived stem cells in adipose tissues from human cadavers. Journal of Plastic, Reconstructive \& Aesthetic Surgery. Oct., 31; 63 (10): 1717 22, 2010.

6- Faustini M., Bucco M., Chlapanidas T., Lucconi G., Marazzi M., Tosca M.C., Gaetani P., Klinger M., Villani S., Ferretti V.V. and Vigo D.: Nonexpanded mesenchymal stem cells for regenerative medicine: Yield in stromal vascular fraction from adipose tissues. Tissue Engineering Part C: Methods. Sep., 2; 16 (6): 1515-21, 2010.

7- Rohrich R.J., Sorokin E.S. and Brown S.A.: In search of improved fat transfer viability: A quantitative analysis of the role of centrifugation and harvest site. Plastic and reconstructive surgery. Jan., 1; 113 (1): 391-5, 2004. 
8- Francis M.P., Sachs P.C., Elmore L.W. and Holt S.E.: Isolating adipose-derived mesenchymal stem cells from lipoaspirate blood and saline fraction. Organogenesis. Jan., 1; 6 (1): 11-4, 2010.

9- Bowen R.E.: Stromal Vascular Fraction from Lipoaspirate Infranatant: Comparison Between Suction-Assisted Liposuction and Nutational Infrasonic Liposuction. Aesthetic Plastic Surgery, 40 (3): pp. 367-371, 2016.

10- Buschmann J., Jao S., Harter L., Hemmi S. and Welti M.: yield and proliferation rate of adipose derived stromal cells as a function of age body mass index and harvest site increasing the yield by use of adherent and supernatant fractions cytotherapy, 15: 1098-1105, 2013.

11- Yu G., Wu X., Dietrich M.A., Polk P., Scott L.K., Ptitsyn A.A. and Gimble J.M.: Yield and characterization of subcutaneous human adipose-derived stem cells by flow cytometric and adipogenic mRNA analyzes. Cytotherapy, 12 (4): pp. 538-546, 2010.

12- Yang M.T., Fu J., Wang Y.K., Desai R.A. and Chen C.S.: Assaying stem cell mechanobiology on microfabricated elastomeric substrates with geometrically modulated rigidity. Nature Protocols, 6 (2): pp.187-213, 2011. 